\title{
Assessing the uncertainty on particle size and shape: Implications for ESR and OSL dating of quartz and feldspar grains
}

\author{
M. Duval a, b, *, I. Campaña a , V. Guilarte a, L. Miguens a , J. Iglesias a , S. González Sierra a \\ a Centro Nacional de Investigación sobre la Evolución Humana (CENIEH), Burgos, Spain \\ ${ }^{\mathrm{b}}$ Research School of Earth Sciences, The Australian National University, Australia
}

\section{H I G H L I G H T S}

- Grain size and shape are two important parameters in ESR and OSL dating of sediment.

- We measure grain size and shape of 19 sediment samples by static image analysis.

- Grains should be in general approximated to smooth slightly elongated ellipsoids.

- We identify the sources of uncertainty influencing grain size and shape.

- The Impact of these results on the dose rate evaluation is quantified.

\section{A R T I C L E I N F O}

\section{Article history:}

Available online $\mathrm{xxx}$

\section{Keywords:}

ESR dating

OSL dating

Quartz

Feldspar grains

Size

Shape

Beta dose attenuations

\begin{abstract}
A B S T R A C T
Grain size and shape are two important parameters in Electron Spin Resonance (ESR) and Optically Stimulated Luminescence (OSL) dating of sediment, since they have a direct impact on several correction factors that are used for evaluating the dose rate. These parameters were evaluated by static image analysis for a wide range of quartz and feldspar grain samples. Our results indicate that there are many factors that may influence the final grain size and shape. Overall, grains are not perfect spheres, but should be rather approximated to smooth slightly elongated ellipsoids, with a width that is on average about $25 \%$ smaller than the length. For multiple grains dating, this may have an influence of a few percents on the beta dose rate evaluation, and thus even less on the total dose rate. However, in the case of single grain dating, the impact may be somewhat more significant given the large variability in size and shape between grains that may be encountered in a natural sediment. For beta micro-dosimetry purpose, it may be thus useful to better characterize the single grain that is going to be dated.
\end{abstract}

๑) 2015 Elsevier Ltd. All rights reserved.

\section{Introduction}

Grain size and shape are two important parameters in Electron Spin Resonance (ESR) and Optically Stimulated Luminescence (OSL) dating of sediment, since they have a direct impact on several correction factors that are used for evaluating the dose rate, such as alpha and beta dose attenuations and self doses (e.g. Aitken, 1985). These correction factors have been regularly updated over the last decades, and the published data now available encompass a wide range of grain size, shape and density (e.g. Brennan, 2003; Brennan et al., 1991; Fain et al., 1999; Guérin et al., 2012; Nathan, 2010 and references therein).

\footnotetext{
* Corresponding author. Centro Nacional de Investigación sobre la Evolución Humana (CENIEH), Burgos, Spain.

E-mail address: mathieu.duval@cenieh.es (M. Duval).
}

In contrast there is, however, very little work done on the characterization of these particles: real physical properties such as the size and shape of the grains, as well as their distribution, that are studied for dating purposes are actually very rarely measured. In the standard ESR and OSL dating procedures, grains are assumed to be spheres and the size of a grain is usually expressed as a diameter. A population of grains is usually obtained by sieving, and the size of this population is defined by a range of diameters that correspond to the mesh of the upper and lower sieves that have been used, providing thus maximum and minimum size values, respectively. So far, there is usually no information collected about the grain size distribution, so that it is assumed to be unimodal and centered somewhere within this size range.

However, some analytical techniques offer nowadays the possibility of rapid particle characterizations, such as instruments based on static image analysis that are widely used for quality 
control purposes in pharmaceutical manufacturing (e.g. Das et al., 2013; Gamble et al., 2014; Krupa et al., 2014; Ulusoy and Kursun, 2011). In the present study, a large diversity of sediment samples were analyzed using a Malvern Instruments Morphologi G3, in order to obtain further information about the morphology of the grains. The two main objectives of this work are: (i) to identify the main sources of uncertainty that influence grain size and shape, (ii) to evaluate in what extent these empirical data may have an impact on the dose rate calculated, by comparison with the assumptions that are usually done in ESR and OSL dating of quartz or feldspar grains.

\section{Material and methods}

\subsection{Samples}

We selected 19 sand samples from various origins. Samples CUL1001 to CUL1004 were collected at Cúllar de Baza site, Spain (Alberdi et al., 2001), samples ER1201 to ER1205 are from Errayah site, Algeria (Derradji, 2006), while those labeled GON1303 and GON1317-21 are from the Gona area, Ethiopia (Quade et al., 2008). The other four are commercial natural sand samples: three of them are silica sand samples (MS1, MS2 and MS3) and one is mainly made by Potassium Feldspars (MF5). MS1 is a normalized sand (ref. CEN-UNE-EN 196-1) from Instituto de Ciencias de la Construcción Eduardo Torroja (Madrid) with initial granulometry $<2 \mathrm{~mm}$ and a certified content of $\mathrm{SiO}_{2}>98 \%$. MS2 is a white sand of initial granulometry between 180 and $500 \mu \mathrm{m}$ coming from the Stampian (Oligocene) Fontainebleau sand formation (France), which is known to be made by a fined-grain, well-sorted and high purity quartz sand (with $\mathrm{SiO}_{2}$ content > 99.5\%) (French and Worden, 2013). MS3 is a siliceous sand (ref. A-S70) from the Arija Quarry (Spain) and delivered by Sibelco, with a content of $\mathrm{SiO}_{2}>90 \%$ and an initial granulometry $<1 \mathrm{~mm}$ (technical specifications provided by Sibelco). Finally, MF5 is made by potassium feldspars from Carrascal del Río Quarry (Spain), which were obtained from feldspar-rich sands by flotation techniques. Technical specifications provided by Incusa (ref. FK-D) indicate an initial granulometry $<700 \mu \mathrm{m}$ a concentration in felsdpars of $\sim 93 \%$, including $\sim 70 \%$ and $23 \%$ of K-feldspars and Na feldspars, respectively, and $~ 7 \%$ of quartz.

All these samples were prepared and analyzed at the Centro Nacional de Investigación sobre la Evolución Humana (CENIEH, Spain).

\subsection{Preparation}

Raw sediment samples were first sieved with Retsch test sieves of $200 \mathrm{~mm}$ diameter using size openings (nominal size) ranging from $2 \mathrm{~mm}$ to $50 \mu \mathrm{m}$. Then, one or several grain size fractions were selected between $300 \mu \mathrm{m}$ and $50 \mu \mathrm{m}$ depending on the samples. $\mathrm{HCl}(36 \%)$ was used to dissolve carbonates and $\mathrm{H}_{2} \mathrm{O}_{2}(30 \%)$ to eliminate organic matter. For all samples except MF-5, heavy minerals and feldspars were removed with Sodium Polytungstate at $\mathrm{d}=2.72$ and $\mathrm{d}=2.62$, respectively. An additional separation at $\mathrm{d}=2.58$ was carried out for sample MF5, in order to eliminate the plagioclase feldspars between $d=2.62$ and $d=2.58$ (Wintle, 1997).

\subsection{Static image analysis}

Static image analyses were performed with a Malvern Instruments Morphologi G3 operated by the Morphologi software 7.41 (supplementary information Fig. S1). This equipment is designed to characterize the shape and size of particles, but has been so far rarely used for sedimentological purpose (e.g. Campaña et al., 2013). It produces automated analysis of two-dimensional
(2D) images of three-dimensional (3D) particles, providing a series of statistical parameters for each particle analyzed. A measurement is made in three steps. The sample is first dispersed by air injection onto a glass plate and then analyzed underneath a set of microscope optics with different magnifications coupled with a digital camera for high resolution image captures. A range of parameters may be finally evaluated to characterize size and shape for each grain of a given dispersion. Further details may be found in the Morphologi G3 User manual (2010).

The volume of sediment sample inserted in the Sample Dispersion Unit (SDU) was between 20 and $40 \mathrm{mg}$ for each measurement. A specific Standard Operation Procedure (SOP) was designed for this work (see details in supplementary information Table S1), including optics selection, size of the studied area and a detection threshold level, to minimize possible sources of errors (Merkus, 2009). Calibration of magnification and focus was automatically done prior to any measurements, by using the calibration gratings that are inserted on the sample carrier holder and certified by the National Physical Laboratory and NIST (further details may be found in the Morphologi G3 User Manual, 2010). A single measurement usually took $\sim 50 \mathrm{~min}$. At the end of the measurement, the final set of analyzed particles was visually checked and manually filtered: the particles that may induce a bias in the statistical estimates were removed, like fibrous particles or particles that were overlapping or touching and were erroneously considered as a single particle by the software. Among all the variables that can be evaluated for each sample dispersion, the following ones were selected for the present study (a basic description of each of them may be found in Supplementary Information): Circle Equivalent (CE) diameter, Length, Width, Circularity, Convexity and Aspect ratio. These size and shape parameters were calculated for each grain from which mean values and standard deviations were extracted in order to characterize each sample. Numerical values are shown in Table S2.

Scanning Electron Microscope (SEM) pictures were also taken for some of the samples, with a FEI Quanta 600 instrument (see Roebroeks et al., 2012, supplementary information, for further details about the equipment). Fig. 1 illustrates the variability in shape and size of the grains that may be encountered in each sample.

\section{Results}

\subsection{Shape parameters}

Convexity values vary within narrow range from 0.959 (CUL1104) to 0.991 (MF-5), indicating that grains have overall a quite smooth shape. Circularity ranges from 0.879 (GON1320) to 0.944 (MF-5), while aspect ratio values are between 0.694 (MS1_50-100 um) to 0.780 (MS1_150-200 um). Mean circularity and aspect ratio values over the 26 samples are of $0.907 \pm 0.022$ and $0.745 \pm 0.024$, respectively. These values derived from the analysis of $2 \mathrm{D}$ images indicate that the particles do not have a circular shape, since a value of 1 would be expected for both of them in the case of perfect circles. In addition, a look at the shape factor values calculated for each individual grain indicate an extreme variability within a given sample: as an example, the aspect ratio is ranging from 0.427 to 0.998 and the convexity from 0.836 to 0.999 for sample ER1203, showing that some grains may be almost perfectly circular while other are very elongated, some are of very smoothed aspect and other have a more irregular shape.

Interestingly, different patterns may also be identified for each site: grains from Errayah have apparently on average a more circular (mean circularity $=0.930$ ) and smoothed aspect (mean convexity $=0.985$ ) than those from Cúllar de Baza and Gona (this difference may also be clearly observed in Fig. 1). The latter two 

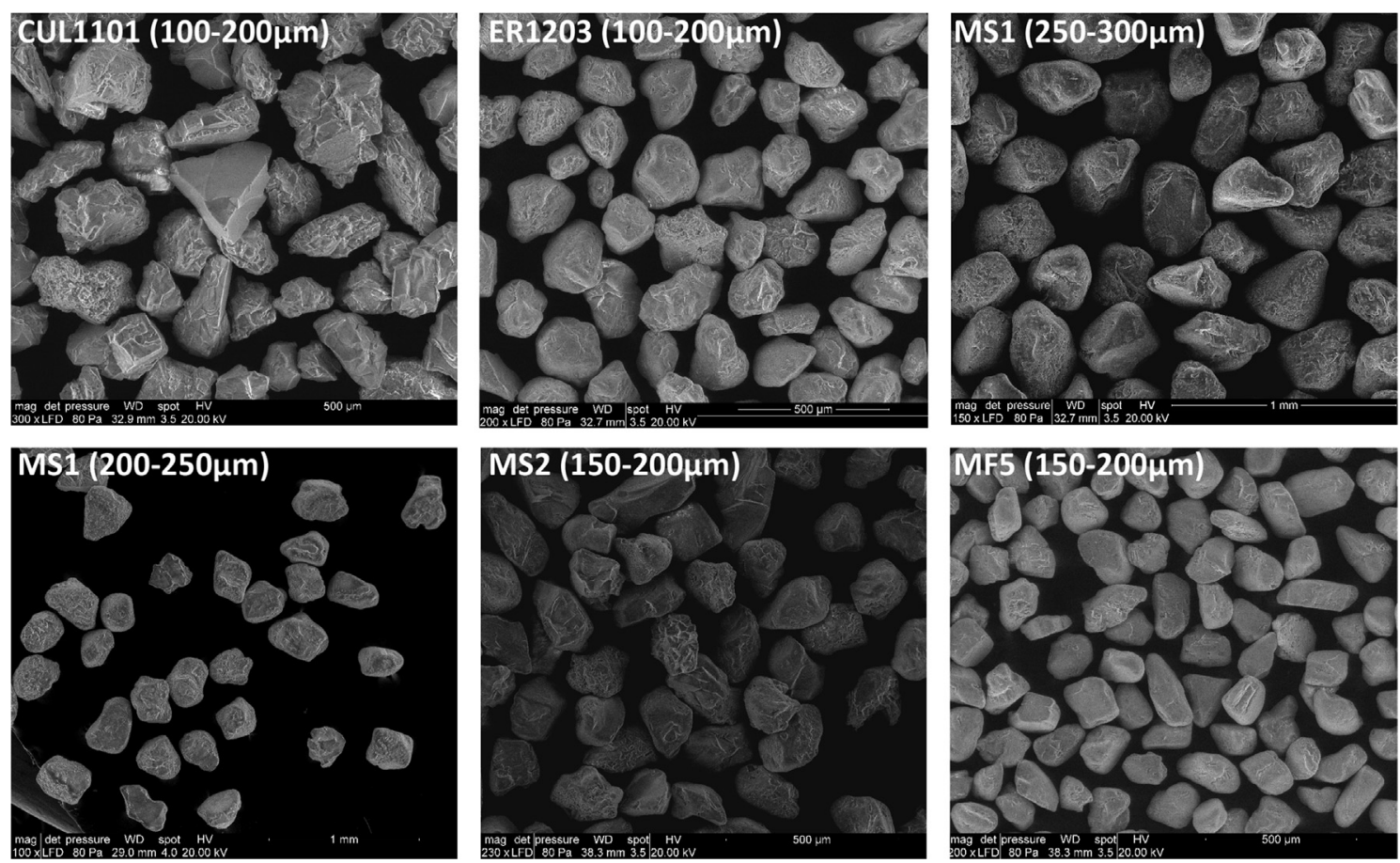

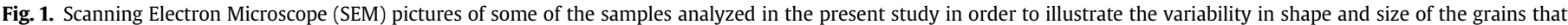
may be encountered within a given grain size fraction. Pictures were taken with a FEI Quanta 600 at CENIEH (Spain).

sites have grains with similar characteristics (mean circularity $=0.884$ and 0.887 ; mean convexity $=0.962$ and 0.970 ). In addition, a focus on MS1 sample indicates that a slight increase of the circularity might also be observed with the increase of the grain size and the aspect ratio goes from 0.694 (50-100 $\mu \mathrm{m}$ fraction) to $0.77-0.78$ for grain fractions $>150 \mu \mathrm{m}$, whereas the convexity remains apparently unchanged.

\subsection{Size parameters}

There is a large variability in the mean diameter values calculated among the samples (Table S2). For samples \#1 to \#15 whose nominal sieve mesh range is $100-200 \mu \mathrm{m}$, the mean diameter varies from $151.1 \pm 28.6 \mu \mathrm{m}$ (CUL1003) to $227.1 \pm 31.9 \mu \mathrm{m}$ (GON1317). The spread of the distribution (1 standard deviation) is also sample dependant and ranges from 14.1\% (GON1317) to $48.6 \%$ (MS3_100-150 $\mu \mathrm{m}$ ). It is on average around $17.2 \%$, but two samples show different characteristics with $\sigma>25 \%$. Indeed, CUL1004 and MS3_100-150 $\mu \mathrm{m}$ have a high proportion of grains whose CE diameter is lower than the size opening of the lower sieves, 7.6 and $29.4 \%$ respectively for these same samples, whereas this proportion does not exceed $1.5 \%$ for the other samples. These data suggest that optimum particle positioning during sieving could not be achieved to allow the smallest grains to pass through the openings (Merkus, 2009). The lower sieving efficiency observed for these two samples is very likely due to an overloading of the sieve by sediment.

However, perhaps the most striking observation is that $15 / 26$ samples show a mean CE diameter that is higher the nominal aperture size of the upper sieves. For example, within the set of samples from the Gona area whose grain size fraction is $100-200 \mu \mathrm{m}$, the mean $\mathrm{CE}$ diameter is ranging from $188.8 \pm 41.8 \mu \mathrm{m}$ (GON1320) $\mu \mathrm{m}$ to $227.1 \pm 31.9 \mu \mathrm{m}$ (GON1317). As another example, each fraction of sample MS1 has a mean CE diameter higher than the nominal size of the upper sieve that has been used (Table S2). However, this trend is not systematic, since, in contrast, the four samples from Cúllar de Baza $(100-200 \mu \mathrm{m})$ have a mean CE diameter between 150 and $180 \mu \mathrm{m}$.

\subsection{Summary}

These data show the large variability between the samples in term of size and shape of grains. The results derived from 2D images show that grains are not perfect spheres (i.e. the 3D analogue of a circle), but should be rather approximated to smooth slightly elongated ellispoid (i.e. the 3D analogue of an ellipse), with a width that is on average about $25 \%$ smaller than the length. In addition, there is apparently a clear difference between the standard mesh of the sieves and the real grain size distribution measured by static image analysis. The principal sources of uncertainty that may potentially directly affect the grain size and shape will be individually discussed in the next section.

\section{Discussion}

4.1. Identifying the sources of uncertainty associated to grain size and shape

\subsubsection{Theory of sieving}

First of all, our results indicate that a distinction has to be done between the sieve aperture size, or sieve opening, and the diameter of a particle. Test sieves are usually made of square meshes and defined by a nominal aperture size, which is the distance between two adjacent parallel wires measured in the mid position. In the case of perfect spheres, this opening size corresponds to the diameter of particles that would just pass through the aperture. However, if the particles are not true spheres, then this would rather correspond to the second largest dimension of the particle.

Sahu (1965) showed that sieves sort material according to their size, but also their shape and roundness. If the shape of the particle is an ellipsoid or tabular, rather than spherical, then the sorting will 
depend on their smallest cross sections: the two smaller dimensions of the particles determine whether they can pass an aperture (see also Merkus, 2009). An ellipsoid may be usually defined by three axis, usually called $a, b$ and c, defined as minor, intermediate and major diameter (length of the particle), respectively. For a nominal aperture size of $\mathrm{X} \mu \mathrm{m}$, the range of possible variations for each dimension of non-spherical grains passing just through the aperture would be (Sahu, 1965): between $\mathrm{X} \mu \mathrm{m}$ and $+\infty$ for the major diameter, between $X$ and $X^{*} \sqrt{ } 2 \mu \mathrm{m}(=$ diagonal of the aperture) for the intermediate diameter and between 0 and $\mathrm{X} \mu \mathrm{m}$ for the minor diameter.

Consequently, for non-spherical particles, the main dimension controlling the sorting of the grains is the so-called intermediate diameter. For example, for standard mesh of 50, 100, 200 and $300 \mu \mathrm{m}$, grains passing through may have an intermediate dimension in the range of from 50 to $71 \mu \mathrm{m}, 100-141 \mu \mathrm{m}$, 200-283 $\mu \mathrm{m}, 300-424 \mu \mathrm{m}$, respectively. If we assume that the grain width measured by the static image analysis may be used as a fair estimation of this intermediate dimension, the proportion of grain having a width higher than the nominal aperture size of the upper sieve is $<<1 \%$ in our dataset which is consistent with the theoretical considerations.

Static image analysis may characterize shape and size of 2D grains, in particular length and width. Given the possible variations of these particle dimensions that have been observed, this may simply explain why the mean CE diameter calculated by this technique, which is derived from the $2 \mathrm{D}$ area of the grains, frequently exceeds the nominal aperture size of the upper sieve.

\subsubsection{Variability in the size of the apertures within a given sieve}

Sieving process was performed using $200 \mathrm{~mm}$ diameter Retsch test sieves that were manufactured in accordance with the ISO 3310-1:2000(E). This normative reference defines, among other points, the tolerance on the aperture size of the sieves. This is described by three main parameters for a given nominal size: each sieve should not exceed (i) a maximum aperture size (X), (ii) an average aperture size (Y) and (iii) a maximum standard deviation $(\sigma 0)$ of the aperture sizes. Inspections for oversized apertures (tolerance $\mathrm{X}$ ) are carried out on all apertures, while a minimum number of apertures has to be measured over the full diameter of the metal wire cloth in both warp (horizontal) and weft (vertical) dimensions for the two other tolerances. For example, for $200 \mathrm{~mm}$ test sieves, $2 * 80$ and $2 * 100$ apertures have to be measured in both directions for nominal aperture size of 300 to $200 \mu \mathrm{m}$ and 180 to $50 \mu \mathrm{m}$, respectively. Further details may be found in ISO 3310-1:2000(E). Table S3 provides the tolerance values corresponding to the sieves that have been used in the present study.

Actually, if these values are specific for each nominal size, the relative tolerance decreases as soon as the nominal aperture size of the sieve increases. For example, for two sieves of nominal aperture size of 300 and $50 \mu \mathrm{m}$, not a single aperture size should exceed 365 and $73 \mu \mathrm{m}$, i.e. $+21.7 \%$ and $+46.0 \%$ above the nominal size, respectively. For these same sieves, it is tolerated an average aperture size within $300 \pm 12 \mu \mathrm{m}$ and $50 \pm 3.3 \mu \mathrm{m}$, with a maximum standard deviation of $25.4 \mu \mathrm{m}$ and $8.5 \mu \mathrm{m}$, corresponding to a coefficient of variation of 8.5 and $17.4 \%$, respectively.

Finally, it is worth reminding that the irregularities in the sieve mesh may not only come from the initial tolerance on the aperture size, but also from the damages due to repetitive use of the sieves, during either the sieving or the cleaning steps. In that regard, some SEM pictures of the sieves that have been used in the present work are shown in Fig. S2, illustrating the variability in the size openings that may be encountered in a given sieve.

\subsubsection{Reliability of the measurements}

Several sources of error may potentially affect the reliability of the results obtained with static image analysis (some examples may be found in Merkus, 2009), such as poor image and particle resolution, overlapping particles, instability of the illumination causing some changes of contrast and sharpness, or incorrect focus and magnification calibration. An automated procedure was designed to avoid these possible problems (see SOP in Table S1): particle resolution threshold was fixed to 1000 pixels, and a control of the light intensity together with a calibration of the magnification were systematically performed before each measurement.

Another source of uncertainty is the precision afforded by the instrument over repeated measurements. One sample (MS2_100150) was successively measured 3 times after one single dispersion in order to evaluate the repeatability of the measurements. Numerical values may be found in Table S4. The number of grains analyzed as well as the values of all the variables showed very little variation from one measurement to another: size and shape factors such as diameter, length, width, circularity, convexity and elongation vary within narrow range, by $<0.1 \%$. These results indicate that the inherent precision of the Morphologi G3 is significantly high.

However, perhaps the major challenge with this kind of analysis is to make sure that the $20-40 \mathrm{mg}$ of sample analyzed is effectively representative of the whole sediment sample. To evaluate this uncertainty, several sediment samples of various grain size fractions were split into three subsamples with a Quantachrome Rotary Micro Riffler MRR-11 in order to ensure an homogenous division. Each subsample was then measured with the Morphologi G3. Results are shown in Table S5. Despite some significant variations in the number of grains analyzed from one subsample to another of a given sample (up to $41 \%$ ), the results are nevertheless highly consistent: size and shape parameters such as diameter, length, width, circularity, convexity and aspect ratio vary within narrow range, by $<1.15 \%$, i.e. significantly smaller than the standard deviation associated to each parameter. This value may be considered as a good estimate of the uncertainty associated to sample dispersion and homogeneity. These results suggest that in the case of a wellsorted sediment showing an unimodal Gaussian-like distribution, a single measurement is enough to get meaningful results, as soon as the subsample has been obtained with a sample divider, i.e. in a way that ensures the representativeness of the whole sample.

\subsubsection{Characteristics of the raw sediment}

Obviously, the mean values and standard deviations obtained for each size and shape parameters are also directly dependant on the characteristics of the raw sediment. For example, for a given 100-200 $\mu \mathrm{m}$ fraction, one may reasonably assume that a silty sediment would provide a somewhat smaller mean particle diameter than a coarse sand, provided the shape of the grains do not differ too much. The grain size distribution of the raw sediment may have also an impact on the results, like in the case of a bimodal distribution. In that case, mean values would obviously not be accurate proxies for the sample. However, it is very unlikely to have this case in such a short size fraction of a natural sediment, whereas this may be much more frequent for samples that have been etched with HF (Duval et al., 2014).

\subsection{Implications for dose rate evaluation}

Sieves sort grains according to their diameter, if these particles are spherical, or to their intermediate diameter for non-spherical particles. However, as one may have expected, our results show that grains have a rather irregular shape, probably on average closer to a spheroid or an ellipsoid. Static image analysis allows the characterization of the grains in $2 \mathrm{D}$, one being the length, and the 
other, the width, being either the intermediate or minor diameter. Statistically, there is more probability that the grains remain oriented on their 2 largest dimensions, i.e. the length and width may probably correspond to major and intermediate diameter, $c$ and $b$, respectively. The value of the minor diameter (a) should range between 0 and $b$. The analyses of the various samples show that the aspect ratio (width/length) is on average of $0.745 \pm 0.024$.

To evaluate the impact of these observations on the beta dose rate calculations, we selected two samples: CUL1101 and GON1307. Even if both samples are from the $100-200 \mu \mathrm{m}$ fraction, and have a somewhat similar shape with an average aspect ratio around 0.75 , the average grain size was shown to be nevertheless very different, with a mean CE diameter around $150 \mu \mathrm{m}$ and $225 \mu \mathrm{m}$, respectively. Three different scenarios cases may be envisaged. Beta dose rate were first calculated assuming spherical particles (i.e. the standard assumption in ESR/OSL dating). Imagining that no information is available about the grain size distribution, a mean diameter of $150 \mu \mathrm{m}$ was assumed (case \#1). Secondly, grains were still assumed to be spherical, but the mean diameter was taken from the results obtained by static image analysis (case \#2). Finally, grains were considered as being irregular, either prolate spheroids (relative axis length, $\mathrm{a}=\mathrm{b}=2$ and $\mathrm{c}=3$ ) of apparent aspect ratio $=0.67$ (case \#3), or tri-axial ellipsoid (relative axis length, $\mathrm{a}=2, \mathrm{~b}=3$ and $\mathrm{c}=4$ ) of apparent aspect ratio $=0.75$ (case \#4). Beta dose rate calculations were performed using beta attenuations for spherical grains from Guérin et al. (2012). For non-spherical grains, the values were taken from Nathan (2010), using the mean width (= diameter b) as a proxy for the size of the grain. From all the shape considered by Nathan (2010), the prolate spheroids and tri-axial ellipsoid were those that were the closest to the measured mean aspect ratio. Results are shown in Table 1.

Taking case \#1 as a reference, assuming spherical grains using the mean CE diameter value measured by static image analysis would lead to a beta dose rate lower by about 3\% for sample GON1307. However, as expected, the result remains the same for sample CUL1101, since assumed diameter and measured diameter are very close. In contrast, using these empirical values and if grains are approximated to spheroids or ellipsoids, the external beta dose rate would be the same as that for case \#1 for sample GON1307. In comparison, cases \#3 and \#4 would generate a beta dose rate higher by about $2 \%$ than with the standard assumption. Such systematic deviations of a few percents should perhaps not be neglected for the beta dose rate evaluation, but are nevertheless very small when considering the total dose rate, most likely $<<1 \%$.

Consequently, for multiple grain analysis, the spherical assumption, even incorrect, apparently do not induce any significant systematic error. In the future, it would be useful to complete the present study by analyzing a larger number of samples in order to cover a wider range of variability in terms of shape and size of grains, but if the spherical hypothesis has to be kept, it could be

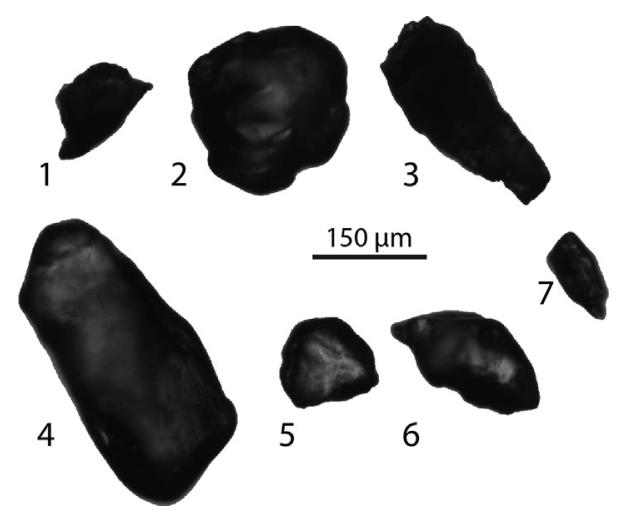

Fig. 2. Selection of several grains from sample ER1203 showing some extreme shape and size characteristics. Pictures were taken during static image analysis performed with a Morphologi G3.

nevertheless recommended to use the real, measured, size of the samples that are studied for dating purpose in order to minimize this uncertainty.

In terms of random error, the relative variability of the $\mathrm{CE}$ diameter among the different grains of a given sample is around $17 \%$ on average ( 1 standard deviation) for the 26 samples measured (Table S2). For samples CUL1101 and GON1307, results yielded a mean CE diameter of $152.7 \pm 30.6$ and $227.1 \pm 31.9$ ( 1 standard deviation), corresponding to a relative variability of $20.1 \%$ and 14.1\%. This uncertainty on the grain size has nevertheless quite a small impact on the beta attenuation factors for spherical particles (taken from Guérin et al., 2012): these factors may vary between $0.9 \%$ and $1.7 \%$ for sample CUL1101 and between $0.9 \%$ and $1.4 \%$ for sample CUL1101 depending on the radioelement considered. Finally, although this uncertainty is actually very small in comparison with other sources of uncertainty involved in the evaluation of the total dose rate (e.g. water content, internal dose rate, radioelement content, depth, etc.), its real impact can hardly be evaluated. Indeed, the present study is based on natural, unetched, grains, whereas ESR/OSL dating is usually carried out on etched grains, and HF etching is known to strongly affect the size of the particles and thus the grain size distribution of the sample, which may become bimodal (Duval et al., 2014).

For single grain dating, the implications may be somewhat greater since there is no averaging effect on grain size, and shape parameters may greatly vary from grain to grain of a given sample. To evaluate the impact, we selected on purpose 7 quartz grains from sample ER1203 (100-200 $\mu \mathrm{m}$ fraction) presenting a large diversity in terms of shape and size, some being very elongated (\#3 and \#4) and others very circular (\#2 and \#5). For example, grain \#4 has a CE diameter of $270 \mu \mathrm{m}$, and its very elongated shape explains

Table 1

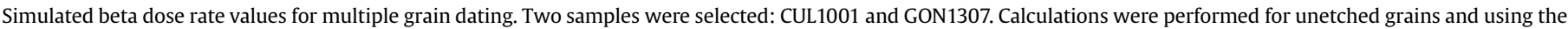

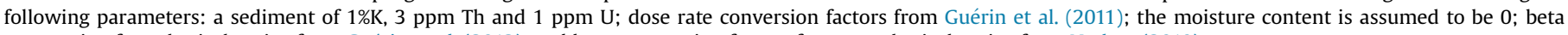
attenuation for spherical grains from Guérin et al. (2012), and beta attenuation factors for non-spherical grains from Nathan (2010).

\begin{tabular}{|c|c|c|c|c|c|c|}
\hline Sample & & Size fraction & Shape & Dimensions & $\begin{array}{l}\text { Beta dose rate } \\
(\mu \mathrm{Gy} / \mathrm{a})\end{array}$ & Ratio to case \#1 \\
\hline \multirow[t]{4}{*}{ CUL1001 } & Case \#1 & $100-200 \mu \mathrm{m}$ & Sphere & assumed diameter $=150 \mu \mathrm{m}$ & 951 & \\
\hline & Case \#2 & $100-200 \mu \mathrm{m}$ & Sphere & measured CE diameter $=150 \mu \mathrm{m}$ & 951 & 1.00 \\
\hline & Case \#3 & $100-200 \mu \mathrm{m}$ & Spheroid & $\mathrm{a}=\mathrm{b}=2, \mathrm{c}=3$ & 967 & 1.02 \\
\hline & Case \#4 & $100-200 \mu \mathrm{m}$ & Ellipsoid & $\mathrm{a}=2, \mathrm{~b}=3, \mathrm{c}=4$ & 968 & 1.02 \\
\hline \multirow[t]{4}{*}{ GON1307 } & Case \#1 & $100-200 \mu \mathrm{m}$ & Spheres & assumed diameter $=150 \mu \mathrm{m}$ & 951 & \\
\hline & Case \#2 & $100-200 \mu \mathrm{m}$ & Spheres & measured diameter $=225 \mu \mathrm{m}$ & 919 & 0.97 \\
\hline & Case \#3 & $100-200 \mu \mathrm{m}$ & Spheroids & $\mathrm{a}=\mathrm{b}=2, \mathrm{c}=3$ & 948 & 1.00 \\
\hline & Case \#4 & $100-200 \mu \mathrm{m}$ & Ellipsoids & $a=2, b=3, c=4$ & 949 & 1.00 \\
\hline
\end{tabular}


Table 2

Simulated beta dose rate values for single grain dating, using 7 grains from sample ER1203 as an example. Calculations were performed for unetched grains and using the same parameters previously indicated in caption of Table 1 .

\begin{tabular}{|c|c|c|c|c|c|}
\hline \multirow[b]{2}{*}{ Shape } & \multicolumn{3}{|c|}{ Beta dose rate $(\mu \mathrm{Gy} / \mathrm{a})$} & \multicolumn{2}{|l|}{ Ratio } \\
\hline & Spheres & Spheres & Spheroidsor Ellispoids & & \\
\hline Size & Diam. $150 \mu \mathrm{m}$ & CE diameter & & & \\
\hline Case & \#1 & \#2 & \#3 & $2 / 1$ & $3 / 1$ \\
\hline Grain \#1 & 951 & 969 & 943 & 1.02 & 0.97 \\
\hline Grain \#2 & 951 & 926 & 953 & 0.97 & 1.03 \\
\hline Grain \#3 & 951 & 940 & 943 & 0.99 & 1.00 \\
\hline Grain \#4 & 951 & 901 & 943 & 0.95 & 1.05 \\
\hline Grain \#5 & 951 & 965 & 953 & 1.01 & 0.99 \\
\hline Grain \#6 & 951 & 954 & 943 & 1.00 & 0.99 \\
\hline Grain \#7 & 951 & 982 & 943 & 1.03 & 0.96 \\
\hline
\end{tabular}

why it passed through the $200 \mu \mathrm{m}$ mesh. In contrast, grain \#7, whose CE diameter and width are of 80.5 and $58.8 \mu \mathrm{m}$, respectively, should have passed through the $100 \mu \mathrm{m}$ mesh of the lower sieve, but did not. Pictures and numerical data derived from the static image analysis are shown in Fig. 2 and Table S6. Beta dose rate were calculated for each grain assuming three different size and shape parameters (Table 2). In the first scenario, grains were assumed to be spheres of $150 \mu \mathrm{m}$ diameter, since there is no way with sieves only to get further information about grain diameter. Then, grains were assumed to be spherical, but using the diameter obtained by static image analysis. Finally, non spherical grains were considered by taking the shape available from Nathan (2010) that was the closest possible to the measured values (Table S6, column 8). Results show that case \#2 and \#3 may induce a deviation up to 5\% higher or lower than the standard assumed values, which appear thus to be more significant than for multiple grains. It is worth nevertheless reminding that these grains were selected on purpose for their extreme shape and size parameters. Consequently, it is very likely that deviation would not exceed a few percent in general for the beta dose rate evaluation. These results nevertheless show that the diversity in size and shape of individual grains may affect more drastically the beta dose corrections for single grain dating.

\section{Conclusion}

Size and shape are two parameters that are closely related: by definition, it is virtually impossible to define the size of a particle if its shape is unknown. In ESR and OSL dating, grains are assumed to be spheres. Based on our results, this assumption is incorrect. Grains should rather be approximated to spheroids or ellipsoids. From our dataset, the shape of the grains varies within quite narrow range, with high circularity and aspect ratios around 0.75 . However, despite these observations, the correction for grain shape may produce an uncertainty of only a few percent in the beta dose rate evaluation, and thus even less for the total dose rate. This uncertainty may nevertheless be more important for single grain dating.

If the spherical assumption is kept for the dose rate evaluation, it would probably be more correct to effectively measure the size of the grains. This is why we would suggest to systematically run a static image analysis prior to HF etching on a subsample of a few tens of $\mathrm{mg}$ in order to better define the real initial size and shape of the grains. In that regard, it would be especially useful for the ESR and OSL dating community if beta attenuations values as presented by Nathan (2010) could be produced for a wider range of size and shape.

Our results show that static image analysis is a useful tool to quickly $(<1 \mathrm{~h})$ characterize the size and shape of the particles. It can help to evaluate the spread of the grain size distribution, but also to check the quality of the sieving. Among the main limitations of the technique, one should keep in mind that results are derived from $2 \mathrm{D}$ pictures of $3 \mathrm{D}$ particles. One dimension is missing (the thickness), even it is highly probable that this dimension is lower than the particle width that is measured by the instrument. One way to evaluate the thickness of the grains could possibly be through the light intensity calculated for each particle, but this would not be straightforward given that it may also strongly depend on the mineralogy and opacity of each grain. Finally, even in the case of well-sorted grains, a wide range of shape and size may be encountered in any natural sediment given all the sources of uncertainty that are involved, and it may be especially crucial to use this fast characterization procedure for single grain OSL dating, where an accurate micro-dosimetry is required.

\section{Acknowledgments}

This study was partially sponsored by a project from the Spanish Ministry of Science and Innovation (Grant number: CGL201016821). We thank our colleagues archaeologists, R. Sala (IPHES), M. Sahnouni (CENIEH) and S. Semaw (CENIEH) for logistic support and providing access to the sampling sites. MD is currently the recipient of an International Outgoing Fellowship from the People Programme (Marie Curie Actions) of the European Union's Seventh Framework Programme (FP7/20072013) under REA grant agreement PIOF-GA-2013-626474. IC is the beneficiary of a PhD scholarship from the Spanish MINECO (project CGL2012-38434-C03-02).

\section{Appendix A. Supplementary data}

Supplementary data related to this article can be found at http:// dx.doi.org/10.1016/j.radmeas.2015.01.012.

\section{References}

Aitken, M.J., 1985. Thermoluminescence Dating. Academic Press, London. Alberdi, M.T., Alonso, MaA., Azanza, B., Hoyos, M., Morales, J., 2001. Vertebrate taphonomy in circum-lake environments: three cases in the Guadix-Baza Basin (Granada, Spain). Palaeogeogr. Palaeoclimatol. Palaeoecol. 165 (1-2), 1-26.

Brennan, B.J., 2003. Beta doses to spherical grains. Radiat. Meas. 37 (4-5), 299-303.

Brennan, B.J., Lyons, R.G., Phillips, S.W., 1991. Attenuation of alpha particle track dose for spherical grains. Int. J. Radiat. Appl. Instrum. Part D. Nucl. Tracks Radiat. Meas. 18 (1-2), 249-253.

Campaña, I., Pérez-González, A., Benito-Calvo, A., 2013. Caracterización morfológica de granos de arena para la identificación de medios sedimentarios. Utilidad de la técnica Malvern MorphologiG3. In: Baena, R., Fernández, J.J., Guerrero, Y.I (Eds.), El Cuaternario Ibérico: Investigación en el S.XXI. VIII Reunión del Cuaternario Ibérico, Sevilla-La Rinconada. AEQUA, Camas, Sevillas, pp. 141-144. ISBN: 978-84-6955-8601-3.

Das, S.C., Behara, S.R.B., Morton, D.A.V., Larson, I., Stewart, P.J., 2013. Importance of particle size and shape on the tensile strength distribution and deagglomeration of cohesive powders. Powder Technol. 249 (0), 297-303.

Derradji, A., 2006. Le site acheuléen d'Errayah (Mostaganem, Algérie) dans son contexte géologique. Comptes Rendus Palevol 5 (1-2), 229-235.

Duval, M., Campaña, I., Guilarte, V., Miguens, L., Iglesias, J., González Sierra, S., 2014. Assessing the uncertainty on particle size and shape: implications for ESR and OSL dating of quartz and feldspar grains. In: Proceedings of the 14th International Conference on Luminescence and Electron Spin Resonance Dating, Montreal (Canada), p. 45.

Fain, J., Soumana, S., Montret, M., Miallier, D., Pilleyre, T., Sanzelle, S., 1999. Luminescence and ESR dating beta-dose attenuation for various grain shapes calculated by a Monte-Carlo method. Quat. Sci. Rev. 18 (2), 231-234.

French, M.W., Worden, R.H., 2013. Orientation of microcrystalline quartz in the Fontainebleau Formation, Paris Basin and why it preserves porosity. Sediment. Geol. 284-285 (0), 149-158.

Gamble, J.F., Ferreira, A.P., Tobyn, M., DiMemmo, L., Martin, K., Mathias, N., Schild, R., Vig, B., Baumann, J.M., Parks, S., Ashton, M., 2014. Application of imaging based tools for the characterisation of hollow spray dried amorphous dispersion particles. Int. J. Pharm. 465 (1-2), 210-217.

Guérin, G., Mercier, N., Adamiec, G., 2011. Dose-rate conversion factors: update. Anc. TL 29 (1), 5-8.

Guérin, G., Mercier, N., Nathan, R., Adamiec, G., Lefrais, Y., 2012. On the use of the infinite matrix assumption and associated concepts: a critical review. Radiat. Meas. 47 (9), 778-785. 
ISO 3310-1:2000. Test Sieves - Technical Requirements and Testing - Part 1: Test Sieves of Metal Wire Cloth.

Krupa, A., Jachowicz, R., Kurek, M., Figiel, W., Kwiecień, M., 2014. Preparation of solid self-emulsifying drug delivery systems using magnesium aluminometasilicates and fluid-bed coating process. Powder Technol. 266 (0), 329-339.

Merkus, H.G., 2009. Microscopy and Image Analysis. In: Particle Size Measurements. Springer, pp. 195-218.

Morphologi G3 User Manual, 2010. MAN0410, Issue 3.0.

Nathan, R.P., 2010. Numerical Modelling of Environmental Dose Rate and its Application to Trapped-Charge Dating. University of Oxford.

Quade, J., Levin, N.E., Simpson, S.W., Butler, R., McIntosh, W.C., Semaw, S., Kleinsasser, L., Dupont-Nivet, G., Renne, P., Dunbar, N., 2008. The Geology of
Gona, Afar, Ethiopia. In: Geological Society of America Special Papers 446, pp. $1-31$.

Roebroeks, W., Sier, M.J., Nielsen, T.K., De Loecker, D., Parés, J.M., Arps, C.E.S., Mücher, H.J., 2012. Use of red ochre by early Neandertals. Proc. Natl. Acad. Sci. 109 (6), 1889-1894.

Sahu, B.K., 1965. Theory of sieving. J. Sediment. Res. 35 (3), 750-753.

Ulusoy, U., Kursun, I., 2011. Comparison of different 2D image analysis measurement techniques for the shape of talc particles produced by different media milling. Miner. Eng. 24 (2), 91-97.

Wintle, A.G., 1997. Luminescence dating: laboratory procedures and protocols. Radiat. Meas. 27 (5-6), 769-817. 